\title{
GENebu Project: home nebulizer use and maintenance in Italy
}

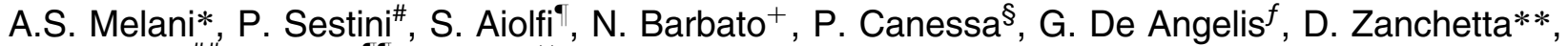 \\ R. De Tullio"\# ${ }^{\#}$ C. Cinti ${ }^{\top \uparrow}$, M. Neri ${ }^{++}$, on behalf of the Associazione Italiana Pneumologi Ospedalieri
} (AIPO) Educational Group

GENebu Project: home nebulizer use and maintenance in Italy. A.S. Melani, P. Sestini, S. Aiolfi, N. Barbato, P. Canessa, G. De Angelis, D. Zanchetta, R. De Tullio, C. Cinti, M. Neri, on behalf of the Associazione Italiana Pneumologi Ospedalieri (AIPO) Educational Group. (C) ERS Journals Ltd 2001.

ABSTRACT: Due to the lack of information on this topic, the Educational Group of the Italian Association of Hospital Pneumologists performed an open, multicentre, observational survey to evaluate home nebulizer practices in Italy.

From May-December 1999, all patients attending one of the 27 participating chest clinics throughout Italy and who were or had been using a home nebulizer in the previous 6 months were consecutively enrolled. All patients completed a selfadministered questionnaire on their current practices of home nebulization.

Of the 1,721 questionnaires delivered, 1,257 were returned with an overall response rate of $73 \%$. Most patients $(82.8 \%)$ reported using their nebulizer for bronchopulmonary symptoms and the remaining patients only used theirs for upper respiratory tract diseases. Subjects using their nebulizer for lower respiratory symptoms were older $(p<0.001)$, predominantly female $(p<0.001)$ and used their nebulizer more frequently $(p<0.001)$. Forty per cent of patients $>60$ yrs old used their nebulizer regularly, at least once a day. More than $60 \%$ of respondents never received any information from healthcare workers on the correct usage of their nebulizer, and $>75 \%$ received no information on nebulizer hygiene and care. Patients who received information on the use and maintenance of their nebulizer from caregivers more commonly attended to these practices $(\mathbf{p}<\mathbf{0 . 0 1})$.

The present survey suggests that home nebulizer use and maintenance in Italy are heterogeneous, and there is the need to implement better nebulizer practice.

Eur Respir J 2001; 18: 758-763.
*U.O. Fisiopatologia Respiratoria, Policlinico Le Scotte, Azienda Ospedaliera Senese, Siena; ${ }^{\#}$ Clinica Malattie Apparato Respiratorio, Università di Siena, Siena; ${ }^{\top}$ U.O. Riabilitazione Respiratoria, Ospedale S.Marta, Rivolta d'Adda; 'Divisione di Pneumologia, Ospedale da Procida, Salerno; ${ }^{\aleph^{2}}$ Divisione di Pneumologia, Ospedale S.Andrea, La Spezia; ${ }^{f}$ U.O. Broncopneumologia e Riabilitazione Respiratoria, Ospedale Forlanini, Roma; **Area Territoriale Tisio-Pneumologica, Vicenza; \#\#U.O. Fisiopatologia Respiratoria, Azienda Ospedaliera Barese, Bari; "Presidio di Tisio-Pneumologia, Azienda Città di Bologna, Bologna; ${ }^{+}$Divisione di Pneumologia, Centro Medico di Tradate, I.C.C.R.S. Fondazione Maugeri, Tradate, Italy.

Correspondence: A.S. Melani, U.O Fisiopatologia Respiratoria, Policlinico Le Scotte, Azienda Ospedaliera Senese, Viale Bracci, I-53100-Siena, Italy. Fax: 390577586196

Keywords: Aerosol, asthma, chronic obstructive pulmonary disease, clinical practice, home care, nebulizer therapy

Received: March 272001

Accepted after revision June 282001

The authors wish to thank Sapio Life, Monza for financial support in performing this survey.
Aerosolization is the first-choice route of administration for the treatment of many respiratory diseases. Pressurized metered-dose inhalers (pMDIs), dry powder inhalers (DPIs) and nebulizers are the devices currently used to administer the aerosolized drugs to the lungs. Among these delivery devices, nebulizers are currently only considered as the first choice for aerosol therapy when the prescribed drug cannot be aerosolized by other systems or in patients unable to draw maximal benefits from both pMDIs and DPIs. In fact, nebulizers are cumbersome, not as efficient as other inhalers and their use and maintenance is timeconsuming.

Guidelines are now available for the standardization of nebulizer therapy [1-3] but they need to be adapted to local habits. Currently, home nebulizer practice seems to be very heterogeneous among different countries [4]. In the UK, the National Health Service usually supplies home nebulizer equipment, as well as its monitoring and servicing [1]; however, the level of supervision from caregivers, generally reported to be good, seemed to be reduced when patients purchased their own home nebulizer [5]. In Italy, subjects who had been prescribed a home nebulizer by their physician purchased the device directly, while drugs for nebulization were partially or fully paid for by the National Health Service. To the authors' knowledge, no formal nebulizer monitoring and servicing system managed by healthcare workers is currently available in Italy, excluding that for cystic fibrosis patients. In Italy, only two district surveys, performed among adults with lower respiratory tract 
diseases, investigated the current practices of home nebulizers in Siena [6-7]. The authors of these surveys suggested that home nebulizer therapy was quite common in their district, and showed that the prescribing physicians seldom advised patients on how to use and maintain their home nebulizers [6-7]. These remarks suggested the need for a nationwide survey to evaluate how home aerosol therapy via nebulizers is performed and whether there is a need for the implementation of guidelines on nebulizer use and maintenance in Italy.

\section{Material and methods}

The GENebu Project was an open, multicentre, cross-sectional, observational study promoted by the Associazione Italiana Pneumologi Ospedalieri (AIPO) Educational Group. Participation was voluntary, but all active members of the group took part in the survey. It was carried out in 27 respiratory centres throughout Italy, from May 1-December 31, 1999. In order to standardize the design of this survey, periodic meetings were held with and telephone contacts made to all participating healthcare workers before and during the study period. The centres encompassed a range of geographical areas and environmental settings, as they were located at different latitudes across Italy (nine centres in northern, 11 in central, and seven in southern Italy) and included highly urbanized as well as rural areas (see centres listed later).

The design of the GENebu Project has been described elsewhere [8]. All of the patients who attended one of the participating centres, had been using a home nebulizer in the 6 months prior to enrolment and agreed to take part in this study were consecutively included. Once they had enrolled, all subjects signed informed consent forms and received a self-administered questionnaire, which they had to fill in at home in order to accurately record the nebulizer equipment used and every detail in the practice of nebulization, and to prevent biased answers. The diagnosis of the respiratory disease, written at enrolment by the investigators, was the only information not provided by the patient. A prepaid envelope with the address of the recruiting centre was also supplied to each patient to facilitate the return of the questionnaire once completed. The questionnaire was printed and computer-scannable and was preliminarily prepared by the AIPO Educational Group members. Its comprehensibility and reliability had also been tested during a preliminary phase by a group of patients that were not enrolled in the present survey; a full copy of the questionnaire has already been published [8] and is available on request from the authors in the original Italian language. The questionnaire included 38 questions on the practices of home nebulization, as well as information about the demographical and clinical characteristics of the participants. The present paper includes answers to the questions on the use and maintenance of home nebulizers. The protocol did not include any objective measurement of the validity of the answers, and no attempt was made to obtain information from patients who failed to return the questionnaire.

\section{Analysis}

Multiple logistic regression was used for analysis of categorical variables. Unless otherwise stated, all logistic models included sex and age to adjust for these possible confounders. A p-value of $\leqslant 0.05$ for a twotailed test was considered significant.

\section{Results}

\section{Demographical and pathological characterisics}

The authors received 1,257 questionnaires from the 1,721 distributed, yielding an overall response rate of $73 \%$. Basic information limited to age, sex and diagnosis of all the patients who received the questionnaire was available from 12 centres. These centres distributed 1,109 questionnaires, 282 of which were not returned to the investigators. Patients who failed to return the questionnaire were younger (median age 55 versus $65 \mathrm{yrs}$, Chi-squared for trend $\mathrm{p}<0.001)$, suffered more often from nose and/or throat diseases $(19.6 \%$ versus $9.3 \%, \mathrm{p}<0.001)$ and acute respiratory conditions $(9.9 \%$ versus $5.0 \%, \mathrm{p}=0.003)$. Sex distribution was similar in the two groups.

The main diagnosis in patients who returned the questionnaire is shown in table 1. More than $85 \%$ of subjects had chronic lower respiratory diseases, mainly chronic obstructive pulmonary disease and asthma. When asked, $74.6 \%$ of patients reported using their home nebulizer only for treating bronchopulmonary conditions, $17.2 \%$ only for upper airways symptoms (nose and/or throat) and $8.2 \%$ for both problems. In the following paragraphs, the group of patients using nebulizers for bronchopulmonary conditions (with or without upper respiratory symptoms) will be differentiated from the group using nebulizers only for nonbronchopulmonary problems.

As shown in figure 1, the age distribution significantly differed between the groups; subjects with bronchopulmonary disease were older $(p<0.001)$. The

Table 1.-Diagnosis of the main respiratory diseases among 1,257 enrolled patients

\begin{tabular}{lr}
\hline Disease & $\mathrm{n}(\%)$ \\
\hline COPD & $519(41.5)$ \\
Bronchial asthma & $345(27.6)$ \\
Nose and throat disease & $129(10.3)$ \\
Lung cancer & $20(1.6)$ \\
Bronchiectasis & $41(3.3)$ \\
Tuberculosis and its sequels & $9(0.7)$ \\
Acute lower respiratory tract infection & $65(5.2)$ \\
Fibrocystic disease & $3(0.2)$ \\
Interstitial lung disease & $28(2.2)$ \\
Other chronic lung disease & $98(7.4)$ \\
\hline
\end{tabular}

COPD: chronic obstructive pulmonary disease. 


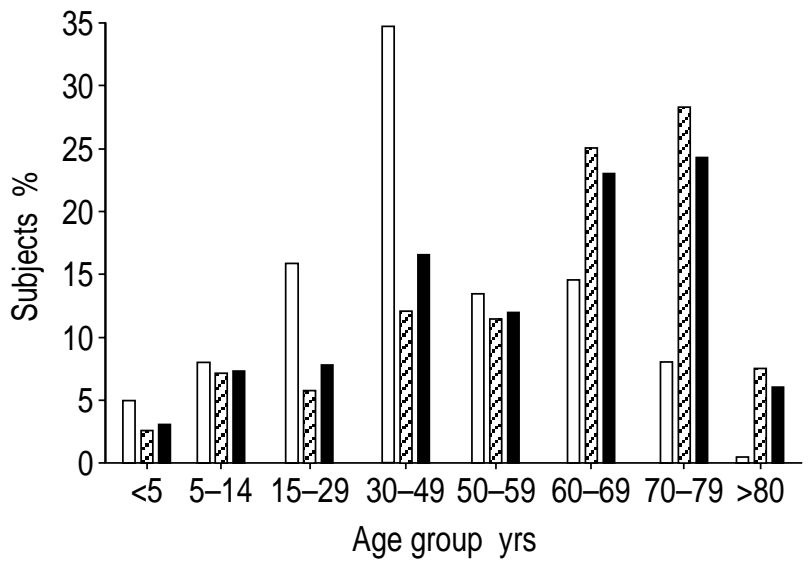

Fig. 1.-Age distribution of the study population. $\square$ : nonpulmonary problems $(n=217) ; \mathbb{Z}$ : pulmonary problems $(n=1,040) ; \mathbf{\square}$ : total population. The group without pulmonary problems was significantly younger $(\mathrm{p}<0.001$, logistic regression adjusted for sex $)$ than the other group.

percentage of females among subjects with bronchopulmonary disease $(60.3 \%)$ was significantly greater than that in the group with nonbronchopulmonary problems $(41.2 \%, \mathrm{p}<0.001)$. In adults, educational background did not significantly differ between the groups, with every level of scholarship represented.

\section{Use of home nebulizers}

As shown in table 2, the time since the subjects first bought their nebulizer was similar in both groups, but the patients with bronchopulmonary disease had newer nebulizers at the time of the study than those
Table 4.-Source of first prescription for home aerosol therapy with nebulizer

\begin{tabular}{lrrr}
\hline Type of physician & \multicolumn{2}{c}{ Pulmonary problems } & \multirow{2}{*}{ p-value } \\
\cline { 2 - 3 } & Yes & No & \\
\hline General practitioner & 37.2 & 42.5 & $<0.001$ \\
Pneumologist & 42.5 & 4.0 & $<0.001$ \\
Allergologist & 3.5 & 5.6 & NS \\
Paediatrician & 8.8 & 18.3 & $<0.05$ \\
Otolaryngologist & 2.9 & 25.0 & $<0.001$ \\
Other specialist & 4.7 & 1.6 & NS \\
No answer & 0.4 & 3.0 & \\
\hline
\end{tabular}

Data are presented as percentage of subjects in the group, unless otherwise stated. NS: nonsignificant. \#: logistic regression adjusted for age and sex.

with upper respiratory symptoms $(\mathrm{p}<0.001)$. The more frequent use of nebulizers by subjects with pulmonary problems can explain this higher turnover. In fact, the number of days in the last year $(\mathrm{p}<0.001)$ and the number of times per day $(p<0.001)$ that they used their nebulizers were significantly greater, as shown in table 3 ; the same patients reported a shorter time since the last use of their home nebulizer $(p<0.001)$. Nevertheless, regular use of home nebulizers, at least once a day, was much more common in patients $>60$ yrs old $(40 \%$ versus $9 \%, \mathrm{p}<0.001$ after adjustment for sex and presence of pulmonary problems).

Table 4 shows the various medical sources of the first advice given to patients in need of home aerosol therapy with nebulizers. Among the medical specialists, mainly paediatricians and otolaryngologists advised the group with only upper respiratory

Table 2. - Time of the first use of home nebulizer and time of purchasing for the current home nebulizer

\begin{tabular}{|c|c|c|c|c|c|}
\hline \multirow[t]{2}{*}{ Time of first use yrs } & \multicolumn{2}{|c|}{ Pulmonary problems } & \multirow{2}{*}{$\begin{array}{l}\text { Time since purchase of } \\
\text { current nebulizer yrs }\end{array}$} & \multicolumn{2}{|c|}{ Pulmonary problems } \\
\hline & Yes & No & & Yes & No*** \\
\hline$<0.5$ & 9.7 & 5.8 & $<0.5$ & 15.8 & 7.2 \\
\hline$\geqslant 0.5<2$ & 11.5 & 16.2 & $\geqslant 0.5<2$ & 17.7 & 18.8 \\
\hline$\geqslant 2<5$ & 26.9 & 18.7 & $\geqslant 2<5$ & 27.8 & 19.1 \\
\hline$\geqslant 5$ & 50.9 & 56.0 & $\geqslant 5$ & 37.3 & 49.8 \\
\hline No answer & 1.0 & 3.3 & No answer & 1.4 & 5.1 \\
\hline
\end{tabular}

Data are presented as percentage of subjects in the group. ${ }^{* * *}: \mathrm{p}<0.001$ versus the group with pulmonary problems, logistic regression adjusted for age and sex.

Table 3. - Frequency of use for home nebulizers

\begin{tabular}{|c|c|c|c|c|c|}
\hline \multirow{2}{*}{$\begin{array}{l}\text { Average frequency of } \\
\text { daily use per yr }\end{array}$} & \multicolumn{2}{|c|}{ Pulmonary problems } & \multirow{2}{*}{$\begin{array}{c}\text { Average frequency of } \\
\text { use per day }\end{array}$} & \multicolumn{2}{|c|}{ Pulmonary problems } \\
\hline & Yes & $\mathrm{No}^{* * *}$ & & Yes & No*** \\
\hline$<15$ days & 28.6 & 55.2 & 1 & 20.4 & 37.3 \\
\hline$>15>60$ days & 37.3 & 33.3 & 2 & 52.4 & 48.8 \\
\hline Regular daily use & 31.4 & 4.0 & $\geqslant 3$ & 26.1 & 6.4 \\
\hline No answer & 2.7 & 7.5 & No answer & 1.1 & 7.5 \\
\hline
\end{tabular}

Data are presented as a percentage of subjects in the group. ${ }^{* *}: \mathrm{p}<0.001$ versus the group with pulmonary problems, logistic regression adjusted for age and sex. 
Table 5. - Source of information of instructions on home nebulizer use and maintenance

\begin{tabular}{lccr}
\hline Source of instruction on correct use & Answers \% & Source of instruction on maintenance & Answers \% \\
\hline Nurse/physiotherapist & 6.5 & Nurse/physiotherapist & 4.2 \\
Physician & 19.3 & Physician & 7.1 \\
Retailer & 13.9 & Retailer & 12.7 \\
Friend/relative & 12.3 & Friend/relative & 10.2 \\
Leaflet from manufacturer & 39.1 & Leaflet from manufacturer & 41.1 \\
None & 11.3 & None & 22.4 \\
\hline
\end{tabular}

Patients could give more than one answer to this item.

symptoms, and pneumologists advised patients with bronchopulmonary disease.

Without any significant difference, $70.5 \%$ of the subjects with bronchopulmonary problems and 64.3\% of those with upper airways disease, respectively, stated that they rigorously followed the indications of the prescribing physician regarding the frequency of nebulizations, while $27 \%$ and $31 \%$ of the same groups reported that they used the nebulizer less often than prescribed, particularly when their symptoms were worse. Patients with bronchopulmonary disease who received a regular daily prescription of home nebulizations, reported the greatest compliance with this treatment $(p<0.01)$. The reported adherence to the treatment did not seem to be influenced by the source of nebulizer prescription, either by a general practitioner or a medical specialist. The patients' source of information on the correct use of home nebulizers are reported in table 5 . Without any difference between the groups, $>60 \%$ of patients reported that they never received any information from healthcare workers or health supply retailers about the use of their home nebulizer. As shown in table 6, patients with a lower level of instruction received advice more often on nebulizer use $(p<0.001)$, while no relationship was observed for sex and age. Nevertheless, none of the subjects lacking instruction on nebulizer use felt this was a problem.

Nearly all the respondents $(98 \%)$ prepared the drug solution in the reservoir just before nebulization. Patients that did not reach dryness threw the residual solution away, but $12 \%$ of subjects used the residue again at varying times after the first interruption. Without any difference between the groups, the

Table 6.-Relationship between level of education of respondents and instruction on correct nebulizer use and maintenance from healthcare workers

\begin{tabular}{|c|c|c|}
\hline $\begin{array}{l}\text { Education } \\
\text { yrs }\end{array}$ & $\begin{array}{c}\text { Patients with } \\
\text { some instructions } \\
\text { on nebulizer use } \\
\text { *** }\end{array}$ & $\begin{array}{l}\text { Patients with some } \\
\text { instructions } \\
\text { on nebulizer } \\
\text { maintenance*** }\end{array}$ \\
\hline
\end{tabular}

\begin{tabular}{lll}
\hline No education & 44.9 & 29.9 \\
$<6$ & 44.9 & 26.5 \\
$\geqslant 6<9$ & 36.8 & 26.2 \\
$\geqslant 9<14$ & 32.8 & 20.6 \\
$\geqslant 14$ & 20.0 & 13.3 \\
\hline
\end{tabular}

Data are presented as $\%$.***: $\mathrm{p}<0.001$, adjusted for age and sex. average duration of each nebulization in $35 \%$ of cases was reported to be $>15 \mathrm{~min}$.

\section{Maintenance of home nebulizers}

The patients' source of information on the correct maintenance of home nebulizers are shown in table 5 . Few healthcare workers attended to these practices; in fact, without any difference between the groups, $>75 \%$ of patients reported that they never received any information from healthcare workers or health supply retailers (usually pharmacists) on nebulizer maintenance. Nevertheless, receiving information from a caregiver (either a physician, nurse, or health supply retailer) was more common in the group with pulmonary diseases $(42 \%$ versus $33 \%, \mathrm{p}<0.05$, after adjustment for age and sex).

Patients with a lower degree of education received more information on maintenance of nebulizers from healthcare workers, as shown in table 6 . No relationship was observed for sex, age and source of medical prescription. Twenty-five per cent of patients did not clean their nebulizer after each use. Many patients disinfected their nebulizer once a week $(20.8 \%)$, while others only disinfected once a month $(13 \%)$, or never $(36.3 \%)$. Nebulizer cleaning and disinfecting practices varied largely, as shown in table 7 . After multivariate analyses, more frequent cleaning and disinfecting was

Table 7.-The most common modalities of nebulizer hygiene

\begin{tabular}{|c|c|c|c|}
\hline \multirow[t]{2}{*}{ Method of cleaning } & \multicolumn{2}{|c|}{$\begin{array}{l}\text { Pulmonary } \\
\text { problems }\end{array}$} & \multirow[t]{2}{*}{ Total } \\
\hline & Yes & No & \\
\hline Rinsing with tap water & 53.5 & 46.8 & 52.2 \\
\hline $\begin{array}{l}\text { Dipping and washing with } \\
\text { soap and water }\end{array}$ & 9.3 & 10.7 & 9.6 \\
\hline Washing in dishwasher & 0.7 & 1.2 & 0.8 \\
\hline Washing with distilled water & 4.2 & 2.4 & 3.8 \\
\hline Washing with ethyl alcohol & 8.4 & 9.1 & 8.6 \\
\hline Washing with hydrogen peroxide & 1.5 & 1.6 & 1.5 \\
\hline $\begin{array}{l}\text { Dipping in water and } \\
\text { heating until boiling }\end{array}$ & 26.5 & 30.2 & 26.8 \\
\hline Washing with bleach & $10.3^{\#}$ & 15.9 & 11.1 \\
\hline $\begin{array}{l}\text { Dipping and washing in a } \\
\text { vinegar solution }\end{array}$ & $8.4^{\#}$ & 4.0 & 7.5 \\
\hline
\end{tabular}

Data are presented as \%. Patients could give more than one answer to this question. ${ }^{\#}: \mathrm{p}<0.02$, bivariate analysis. 
marginally associated with the female sex $(p=0.06)$, significantly associated with younger age $(p<0.02)$ and, interestingly, with receiving instructions from a healthcare worker $(\mathrm{p}<0.001)$. The results did not differ according to the presence of respiratory problems. Even if possible, subjects did not always disassemble the reservoir for cleaning; in fact, $70.1 \%$ dismantled it regularly, $14.3 \%$ sometimes, and $14.6 \%$ never. Among the respondents, $53.2 \%$ always dried the reservoir after every use, whereas $35.1 \%$ never dried the reservoir. Patients who had received some instruction on the necessity of drying the reservoir after each use did so more often than patients without any instruction $(\mathrm{p}<0.01)$. Without any difference between the groups, when asked if they had periodically reviewed the reservoir, only $10.1 \%$ of the patients reported replacing it in accordance with the manufacturer's instruction, whereas $47.3 \%$ changed the reservoir only in case of evident visual or auditory defects (e.g. cracked parts, air leakage) and nearly 40\% never replaced it. Nevertheless, patients who had received instructions from healthcare workers on the need for periodic replacement of the reservoir changed it more effectively than subjects without any information $(p<0.05)$. Six per cent of patients reported the presence of macroscopic residuals in the tubes or the reservoir of their nebulizer.

Healthcare givers never offered to supervise monitoring and servicing of home nebulizers, but the authors' patients did not feel that this was a problem.

\section{Discussion}

Due to the enrolment selection criteria, the present study's population included several applications for home nebulizers and represented a spectrum of all ages of users and respiratory diseases. Many subjects reported using their home nebulizer only on some days in the last year, probably when their symptoms were worse, either during acute respiratory tract infections or occasional episodes of breathlessness. Other patients used their nebulizer at least once a day, and, at the most, several times a day, particularly seen in elderly patients with bronchopulmonary diseases. The present data also suggest that in Italy, a good number of physicians, both specialists and general practitioners, have prescribed and are prescribing home aerosol therapy with nebulizers.

In a survey performed in northern Italy during 1992 1993, 1,104 20-44-yr-old asthmatic subjects reported a compliance to the prescribed aerosol therapy of $\sim 60 \%$ [9]. A slightly higher percentage, around twothirds of the authors' patients, reported total adherence to the prescribed nebulizers. The compliance was particularly good in elderly bronchopulmonary patients who used home nebulizers at least once a day. It has previously been shown that patients may underreport effective adherence to prescribed home nebulizers [10], which may also be the case in the present study. The perceived effectiveness of nebulizer treatment was high in the authors' patients (data not shown), suggesting that the reported adherence to treatment was sufficiently reliable. Similarly, TURNER et al. [11] reported a direct relationship between compliance with home nebulizer treatment and perceived effectiveness of use.

Nevertheless, the present study suggests the need for improvements in the current modalities of home nebulizer use and maintenance in Italy. Optimal nebulization time is considered to be $<10 \mathrm{~min}$, but many of the patients took much longer. Many patients that had a reservoir that could be disassembled did not regularly take it to pieces in order to aid cleaning. Cleaning and careful drying of the nebulizer after each use were not always performed and its disinfection was often occasional and not standardized. Nebulizer equipment sometimes appeared dirty and was often only changed when broken or in cases of evident malfunction. The functions of the nebulizers were not regularly controlled and serviced. Despite the widespread lack of instructions on use and, above all, maintenance of home nebulizers from healthcare workers, the patients never complained. This finding has been seen in a previous study [12] and it has been shown that confidence in nebulizer use does not automatically mean that the practices were appropriate [5]. Interestingly, when healthcare workers provided more information on nebulizer use and maintenance, patients took better care of these practices.

It is widely accepted that in the absence of guidelines, misuse of nebulizers is common and a lack of standardized hygiene procedures for home nebulizers predisposes to bacterial contamination of the therapeutic aerosols and often sustains malfunctions in the delivery systems [1-3]. Guidelines on the correct use and maintenance of nebulizers have recently been published [1-3] and the authors hope that the implementation of these rules by Italian physicians will not only help to improve the prescription of aerosol therapy with nebulizers, but may even teach patients the best practices of home nebulizer treatment and verify whether use and maintenance of nebulizers are effective.

The authors conclude that in Italy, home nebulizer therapy was and remains widespread, with either occasional or regular use for both upper and lower respiratory tract diseases. The use and maintenance of home nebulizers were heterogeneous and often not optimal. The European standards for nebulizer therapy [2, 3] will provide a foundation for the adaptation and implementation of home nebulizer practices in Italy, overcoming the current lack of regulations.

\footnotetext{
Acknowledgements. The authors are grateful to patients who completed the questionnaire and to E. Boccoli, L. Lavazza, G. Trianni, of the Azienda Ospedaliera Careggi, Firenze, for the scanning data.

Participating Centres: In addition to the authors' centres: M. Aliani, Divisione di Pneumologia, I.C.C.R.S. Fondazione Maugeri, Cassano Murge, Bari; G. Anzalone, S.A. di Pneumologia, Ospedale Misericordia e Dolce, Ospedale di Prato, Prato; M. Bonavia, Divisione di Pneumologia, Ospedale La Colletta, Arenzano, Genova; L. Bancalari, Divisione di Pneumologia, Ospedale S.Andrea, La Spezia; V. Capecchi, E. Zagà,
} 
Presidio di Tisio-Pneumologia, Azienda Città di Bologna; V. Cappiello, Divisione di Pneumologia, Potenza; V. Cilenti, P. Marolla, U.O. Fisiopatologia Respiratoria, Istituto Regina Elena, Roma; S. D'Antonio, Ospedale Vannini, Roma; A. Di Gregorio, G. Baldracchi, U.O. Riabilitazione Respiratoria, Ospedale Armanni, Arco di Trento; M. Del Donno, Clinica Malattie Apparato Respiratorio, Università di Parma, Parma; C. Giacomelli, Servizio di Allergologia, Ospedale di Viareggio, Lucca; G. Grande, Clinica delle Magnolie, Caserta; N. Lauletta, Ambulatorio di Allergologia, Ospedale di Carrara, Carrara; C. Maccone, II Broncopneumologia, Ospedale Forlanini, Roma; P. Martucci, U.O. Pneumologia e Urgenze Pneumologiche, Ospedale Cardarelli, Napoli; F. Peccini, M. Dottorini, Medicina Generale, Gubbio, Perugia; M. Pirrelli, U.O. Fisiopatologia Respiratoria, Policlinico Le Scotte, Azienda Ospedaliera Senese, Siena; A. Sena, $33^{\circ}$ Divisione Pneumologia, Ospedale Cardarelli, Napoli; M. Turini, R. Cervone, Ambulatorio di Allergologia, Ospedale di S.Giuseppe, Empoli, Firenze; F. Vannucci, Divisione di Medicina, Ospedale del Ceppo, Pistoia.

\section{References}

1. Muers MF and the British Thoracic Society Nebulizer Project Group. Current best practice for nebulizer treatment. Thorax 1997; 52: Suppl. 2, S1-S106.

2. Boe J, Dennis JH, O'Driscoll BR. European Respiratory Society Nebulizer Guidelines: Clinical Aspects. Eur Respir Rev 2000; 10: 495-583.
3. Boe J, Dennis JH. European Respiratory Society Nebulizer Guidelines: Technical Aspects. Eur Respir Rev 2000; 10: 171-237.

4. Vermeire P. European trends in inhalation therapy. Eur Respir Rev 1994; 4: 89-91.

5. Gregson RK, Warner JO, Radford M. Assessment of the continued supervision and asthma management knowledge of patients possessing home nebulizers. Respir Med 1995; 89: 487-493.

6. Melani AS. [Aerosol therapy via nebulizers in the Siena district]. Rassegna di Patologia dell' Apparato Respiratorio 1998; 13: 229-233.

7. Melani AS, Belardinelli S, Oggioni MR, Valensin PE. [Cleaning methods and bacterial contamination of home nebulizers in the Siena district]. Rassegna di Patologia dell' Apparato Respiratorio 1998; 13: 564 557.

8. Gruppo di studio A.I.P.O. Educazionale. [GENebu Project: some preliminary results]. Rassegna di Patologia dell' Apparato Respiratorio 2001; 16: 454-463.

9. Cerveri I, Zoia MC, Bugiani M, et al. Inadequate antiasthma drug use in the North of Italy. Eur Respir $J$ 1997; 10: 2761-2765.

10. Bosley CM, Corden ZM, Rees PJ, Cochrane GM. Psychological factors associated with use of home nebulized therapy for COPD. Eur Respir J 1996; 9: 2346-2350.

11. Turner J, Wright E, Mendella L, Anthonisen N and the IPPB Study Group. Predictors of patient adherence to long-term home nebulizer therapy for COPD. Chest 1995; 108: 394-400.

12. Laroche CM, Harries AVK, Newton RC, Britton MG. Domiciliary nebulizers in asthma: a district survey. BMJ 1985; 290: 1611-1613. 